\title{
EN TORNO A LA ÉTICA Y LA TRASCENDENCIA EN PSICOANÁLISIS, EL DESEO QUE SIEMPRE ES DESEO ${ }^{1}$ Joan Coderch de Sans ${ }^{2}$ $S E P, I P R$, Barcelona
}

El psicoanálisis relacional hunde sólidamente sus raíces en la ética, pero no en la ética en su sentido formal, aquella que corrientemente denominamos moralismo, si no en la respuesta a las demandas y necesidades del paciente, una ética que enlaza con el anhelo de trascendencia que siempre anida en el espíritu humano y que, por otra parte, debe presidir siempre las relaciones paciente-terapeuta. Hombres y mujeres son seres en los que palpita constantemente el deseo, un deseo inextinguible al que ellos y ellas dan distintos nombres y expresiones, deseo de placer en sus diversas formas, de contacto con los otros, de amistad, de amor y también de poder, de dominio de la naturaleza, del tiempo, del espacio y del curso de su propia existencia. En este trabajo se pone de relieve que la más somera investigación del curso de la historia de la humanidad nos muestra que ésta se mueve siempre empujada por el deseo de algo al que se ha dado distintos nombres y formas, metas, finalidades y consecuciones, abigarradas y constantemente contradictorias entre sí, pero con un denominador común que, finalmente, las enlaza y une, el hecho de que el deseo nunca llega a ser saciado por completo, y ello, al cabo, empuja a una búsqueda que nunca descansa, y en esta búsqueda se llega a lo más sublime del espíritu humano, y también a lo más y degradante de su naturaleza. Las diferentes orientaciones del psicoanálisis relacional, algunas de las cuales son mostradas en las páginas de este escrito, destacan los diferentes medios a través de los cuales los terapeutas tratamos de ayudar a los que sufren y demandan nuestra ayuda, y la conclusión es la de que la mayor parte de ellos son enteramente válidos siempre y cuando vayan acompañados del amor del que han carecido en las primeras etapas de su existencia.

Palabras clave: Ética, Deseo, Psicoanálisis Relacional

Relational psychoanalysis is firmly rooted in ethics, but not in ethics in its formal sense, that which we commonly call moralism, but in the response to the patient's demands and needs, an ethics that is linked to the yearning for transcendence that always nests in the human spirit and which, moreover, must always preside over patient-therapist relationships. Men and women are beings in whom desire constantly throbs, an inextinguishable desire to which they give different names and expressions, desire for pleasure in its various forms, for contact with others, for friendship, for love and also for power, for mastery of nature, of time, of space and of the course of their own existence. In this work it is emphasized that the most cursory investigation of the course of the history of humanity shows us that it is always driven by the desire for something to which it has been given different names and forms, goals, purposes and achievements, variegated and constantly contradictory to each other, but with a common denominator that, finally, links and unites them, the fact that the desire is never completely satiated, and this, in the end, pushes to a search that never rests, and in this search one reaches the most sublime of the human spirit, and also the most degrading of its nature. The different orientations of relational psychoanalysis, some of which are shown in the pages of this paper, highlight the different means by which we therapists try to help those who suffer and demand our help, and the conclusion is that most of them are entirely valid as long as they are accompanied by the love they have lacked in the early stages of their existence.

Key Words: Ethics, Desire, Relational Psychoanalysis

English Title: ON ETHICS AND TRANSCENDENCE IN PSYCHOANALYSIS, THE DESIRE THAT IS

ALWAYS DESIRE

Cita bibliográfica / Reference citation:

Coderch, J. (2021). En torno a la Ética y la Trascendencia en Psicoanálisis, el deseo que siempre es deseo. Clínica e Investigación Relacional, 15 (2): 323-340. [ISSN 1988-2939] [Recuperado de www.ceir.info ] DOI: 10.21110/19882939.2021.150201

CelR Vol. 15 (2) - Octubre 2021 ISSN 1988-2939 - www.ceir.info

(c) Derechos reservados/Copyright de Clínica e investigación Relacionaly los autores. Prohibida la reproducción total o parcial sin autorización expresa. Este material es para uso científico y profesional exclusivamente y puede contener información clínica sensible. Los editores no se responsabilizan de los contenidos de los autores. Dirigir las consultas sobre derechos y autorizaciones a ceir@psicoterapiarelacional.es 
Me adelanto a decir que entiendo por ética algo más que el cumplimiento de los derechos y deberes que obligan a todos los hombres y mujeres, porque ésta es sólo la ética que podemos llamar mínima y formal y que queda resumida en lo que llamamos moral. Para mí la ética es, antes que nada, una actitud; una actitud de respeto, preocupación y responsabilidad frente a uno mismo y por los otros en cuanto a portadores de valores humanos, y también por la Tierra que nos acoge y de la cual dependemos, e igualmente creo que tal actitud ética se expresa en la respuesta a la demanda del otro más allá de las normas legales, e incluso en rebeldía contra ellas cuando es necesario, sin esperar nada a cambio.

En este trabajo trataré de centrarme en el papel de dos dimensiones del espíritu humano desde la perspectiva del psicoanálisis: la ética y la trascendencia, que alientan entrelazadas y fundidas en la relación paciente - analista tal como yo la concibo. Creo que es así porque, a mi juicio, finalmente el sujeto de la ética siempre es el otro, el respeto y cuidado que nos merece, la compasión por su sufrimiento, el sentir nuestra implicación con él en tanto que ser humano, más allá de los preceptos. Y en esta actitud de preocupación por el otro nos trascendemos a nosotros mismos, de forma que podemos decir que, aunque los dos distintos términos pueden engañarnos, en realidad no hay ética sin trascendencia ni trascendencia sin ética.

Siguiendo con la ética que yo deseo para el psicoanálisis, más allá de la imprescindible y propia de la responsabilidad profesional (Slochower, 2018), pienso que ella se halla plenamente representada por Ferenczi a quien, creo que muy acertadamente, califica ÁvilaEspada (2013a) de un innovador de la técnica analítica que recupera el papel del trauma (2013a.p. 84), de manera que podemos decir que son la ética y la técnica inspiradas por Ferenczi las que expresan su espíritu, al que yo he tratado de recoger y dar forma en varias de mis publicaciones en torno al psicoanálisis relacional durante la última década (Coderch, 2006; Coderch, 2010; Coderch y Codosero, 2012; Coderch, Castaño, Codosero, Daurella y Rodríguez-Sutil, 2014; Coderch y Plaza-Espinosa, 2016; Coderch, Codosero, Daurella, Plaza y Sunyé, 2018). Agradezco de todo corazón a mis coautores su participación en este empeño.

$Y$ al acogerme a la autoridad de Ferenczi no me refiero particularmente a algunos o muchos de los escritos de su extensa obra, sino que lo de que de él me atrae es el espíritu que transmite en todo su conjunto. Lo que para mí ha de ser la ética propia del psicoanálisis relacional es la que Ferenczi expresa a través de su preocupación, ante todo, para prestar al paciente la ayuda que precisa con afecto, con paciencia, por encima de reglas y normas, con su disposición a cambiar o modificar su forma de acercarse a él, aceptando posibles 
errores si es el caso, en lugar de escudarse tras la idea de que la falta de mejoría de uno u otro de sus pacientes es debida a su escasa o ninguna colaboración, a su rechazo a conocer la verdad, etc. Yo tengo la seguridad de que Ferenczi amaba a sus pacientes. En su extensa obra aparece el perenne deseo de buscar la mejor manera de aliviar el sufrimiento de quienes han pedido su ayuda, sin importarle rectificar cuando lo considera necesario. $Y$ esta ansia de ayuda le llevó a dar un trato humano a los pacientes y a chocar con Freud y sus inmediatos seguidores, en cierta manera podemos decir que sacrificándose por el bien de sus pacientes. Pienso que la afirmación sin simpatía no hay curación, que figura en el Diario Clínico de 1932, resume todo lo que yo estimo en Ferenczi y aquello que, modestamente, he tratado de que anidara y floreciera en el psicoanálisis relacional que yo planteo ${ }^{3}$.

Creo que con lo que acabo de exponer ha quedado claro el espíritu que juzgo ha de impregnar siempre el psicoanálisis relacional. Pero muy recientemente y a mayor abundamiento, Neri Daurella, que ya nos ha ofrecido otros trabajos acerca de la obra de Ferenczi (2000. 2012, 2013), ha publicado un excelente ensayo (2018), en el que creo adecuado que nos detengamos un poco. En esta última publicación estudia Daurella el advenimiento del psicoanálisis relacional a partir de la obra de Ferenczi, con especial énfasis en el ya citado Diario Clínico. Con admirable claridad, pulcritud en la síntesis y precisión histórica, y apoyada en un gran número de bien seleccionadas referencias, Daurella nos describe el advenimiento del psicoanálisis relacional a partir de la obra de Ferenczi, felizmente reencontrado después de la injusta condena que sufrió por parte de quienes, en su momento, ostentaban el poder en la IPA.

Daurella presenta a Ferenczi como una figura parental para el psicoanálisis relacional y nos recuerda su lucha por destacar la importancia del trauma infantil en el origen del sufrimiento mental de los pacientes, aunque ello le supusiera el rechazo por parte de Freud y de sus inmediatos colaboradores en su empeño por convertir al psicoanálisis en una ciencia de la naturaleza. Destaca Daurella el papel de los traumas infantiles sufridos por el paciente en su niñez como causa fundamental de su sufrimiento emocional. Lo expone con estas palabras:

Cuando Ferenczi empezó a recuperar la importancia de su trabajo en el origen de la patología mental, se produjo un malentendido con Freud. Este pensó que su discípulo estaba recorriendo el camino inverso al que él había recorrido hacía más de tres décadas y no se le ocurrió pensar que Ferenczi estaba ampliando la perspectiva sobre lo que es traumático para un niño más allá de la antigua teoría de la seducción sexual del adulto. En "Confusión de lenguas entre los adultos y el niño" y en "El lenguaje de la ternura y el de la pasión", vemos como subscribe la teoría freudiana de las series complementarias, pero advierte sobre la 
minusvaloración del factor traumático que puede adoptar muy diversas formas: por exceso de pasión del adulto, por sentirse el niño no bienvenido, o por lo que califica de "terrorismo del sufrimiento" (p.4).

Junta Daurella la importancia de la recuperación del papel de los traumas sufridos en la infancia al hecho de que, con ello, Ferenczi realizó una crítica de la terapia psicoanalítica debido a que la actitud del analista distante y pretendidamente neutral, basada únicamente en la interpretación del inconsciente puede ser, en muchas ocasiones, retraumatizante y aun iatrogénica. Por mi parte, y de acuerdo con estas palabras creo que, en gran número de casos, el análisis de las pretendidas "resistencias" y de las pulsiones agresivas del paciente no revelan sino la incomprensión del analista ante la natural respuesta del paciente al sentirse incomprendido y culpabilizado por las interpretaciones de aquel a quien esperaba ayuda.

Concreta Daurella en un punto importante las diferencias entre Freud y Ferenczi:

...Freud reprochó Ferenczi su furor sanandi, y el propio Ferenczi hablaba de su "deseo apasionado de ayudar" (p.108 del Diario Clínico) y reconocía que había tenido que aprender de sus errores gracias a su análisis y a lo que le habían ayudado sus pacientes. Pero a mí siempre me ha parecido que el deseo más apasionado de Ferenczi, coherente con su teoría del origen traumático de la psicopatología, era el de no convertir el análisis en una experiencia de retraumatización. $Y$ todos sus tanteos técnicos, mostrados con toda sinceridad en su diario clínico, a modo de proceso de aprendizaje por ensayo y error, transmitido con gran fuerza emocional, son un intento de no caer en un actitud que él califica de "hipocresía profesional...(P.5).

Creo que con estas palabras Daurella da cuenta del carácter humano y cuidadoso de Ferenczi, quien ponía el bienestar del paciente por encima de todo

Entre otras cuestiones se ocupa preferentemente Daurella de la búsqueda de la respuesta óptima, por parte del analista, frente a las necesidades del paciente. Describe así tal respuesta:

En la respuesta óptima reside la clave para la modificación del inconsciente relacional. Y a lo óptimo solo se llega con una actitud permanente de la búsqueda de la sintonía afectiva, no solo de comprensión cognitiva, de apertura a la co-creatividad en el encuentro entre las dos subjetividades de paciente y analista, de reconocimiento de los fallos, de negociación y renegociación siempre que sea necesario (p.18). 
A mí me parecería difícil que algún analista se escudara en razones de teoría, escuela, tradición o técnica para no dar al paciente, en cada momento, la respuesta óptima a sus necesidades.

Me parece indudable que con respecto al tema de la ética en psicoanálisis los trabajos de D, Orange merecen un puesto de honor (2006,2010, 2012, 2016, entre otros), Sin embargo ahora no me ocuparé de ella por haberlo hecho ya en diversas publicaciones.

Otra aportación reciente merecedora de nuestra consideración acerca de la ética en psicoanálisis es la de André Sassenfeld (2018), quien en un acertado trabajo acerca de los giros del psicoanálisis contemporáneo, dedica un apartado al "giro ético". Para este autor, el interés actual por la ética en psicoanálisis es una respuesta a la sistemática relativización postmoderna de los valores y la moral, con la creciente desorientación por parte de la humanidad en torno a la manera como ha de ser vivida la vida y de aquello que ha de ser considerado bueno o malo para ella. Para Sassenfeld las circunstancias actuales de desorientación y pérdida de influencia de las antiguas tradiciones obligan a reflexionar sobre la dimensión ética del psicoanálisis. Lo expresa así:

Si el psicoanálisis es en primer lugar una terapéutica- y esa es una de las raíces del psicoanálisis contemporáneo en la obra de Ferenczi-, la ética contemporánea es sin lugar a dudas una reflexión sobre aquello que puede ayudar a un paciente a llevar una vida mejor y más satisfactoria (p.301).

Se pregunta, por otra parte, Sassenfeld acerca de qué significado debemos dar al término paciente en el marco del psicoanálisis contemporáneo, y resuelve la cuestión, a mi parecer muy acertadamente, acudiendo a la etimología, el término original griego: pathos, que es padecer. Esto le permite concluir que la meta del tratamiento psicoanalítico es la búsqueda del alivio del sufrimiento. A mí me parece que esta sucinta declaración de la meta del psicoanálisis es la mejor que puede darse. Pienso que todo lo otro que puede decirse son matizaciones y reflexiones acerca de la manera como puede logarse que cese o se atenúe el sufrimiento de quien pide nuestra ayuda. Por mi parte, intento en el trabajo que ahora presento exponer cual creo que debe ser la actitud del analista, con relación a la ética, para lograr este alivio del dolor del paciente y, a la vez, deseo mostrar la estrecha vinculación de esta actitud ética con la apertura a la trascendencia por parte del paciente, en tanto que dimensión inherente a la naturaleza humana.

Y, guiado por el propósito que acabo de mencionar en el párrafo anterior, continuaré transcribiendo y comentado algunas reflexiones del filósofo J.C. Mèlich, discípulo directo del ya fallecido (2017) filósofo y antropólogo LI. Duch (monje benedictino de la Abadía de 
Montserrat) quien, a su vez, lo fue del filósofo marxista Ernst Bloch, a la vez que recoge, en cierto modo, el pensamiento de Schopenhauer. Y hago estas aclaraciones por si ello puede ayudar a comprender mejor la concatenación de ideas que trataré de seguir exponiendo, así como mi propia relación con las mismas.

En su libro Ética de la Compasión (2002) expone Mèlich una concepción de la ética que a mí me parece de un interés excepcional para seguir avanzando en nuestras consideraciones en torno a la ética, en psicoanálisis como en la vida. Nosotros, los analistas, solemos hablar del sufrimiento de los pacientes, pero tal vez como resultado de la regla, tan repetida como imposible de cumplir, de que el analista debe ocultar su personalidad y sus sentimientos, nos parece que hemos de quedar al margen de este sufrimiento, mientras que Mèlich nos habla sin reparos del sufrimiento de la humanidad que todos compartimos. Él insiste en advertirnos del error que supone contemplar a los seres humanos bajo la dualidad naturaleza - cultura, porque la cultura forma parte de la naturaleza humana, el ser humano es un ser naturalmente cultural, y no existen ni podrían existir lo seres humanos extra culturales (Duch, 1999, 2000, 2010; Duch y Mélich, 2004; Duch y Chillón, 2011). Insiste Mélich en que el ser humano es un ser biológico y cultural $a b$ initio (p.39). De manera que, según él, la verdadera tensión no es entre lo innato y lo adquirido sino entre la herencia, es decir, lo recibido, y el proyecto $y$, dicho con otras palabras, entre la realidad, que corresponde a la naturaleza, y el deseo, al que denomina la condición, y afirma que la vida se podría definir como algo que sucede entre la situación heredada y nuestro modo de administrarla, entre pasado, presente y futuro, entre realidad y deseo. $Y$ juzga que esta tensión se encuentra en la base del sufrimiento humano.

Distingue Mèlich entre vida y mundo, ya que vivimos en un mundo heredado pero que no coincide con el mundo de la realidad y trasciende más allá de él, es una trascendencia en la inmanencia, y por esto podemos reconciliarnos con nosotros mismos pero no con el mundo, porque la vida siempre es una tarea, algo que hacer y una experiencia que se nos impone y pesa sobre nosotros. Creo que también nos facilitará la comprensión de las ideas de Mèlich tener en cuenta dos autores a los que él cita con frecuencia, A. Schopenhauer y E. Bloch, de los que yo creo que también puede considerarse como un continuador en lo que concierne al deseo insatisfecho, insaciable, como algo inmanente en el ser humano. Manifiesta Schopenhauer en su imperecedera obra El Mundo como Voluntad y Representación (1818).

La voluntad, que considerada puramente en sí es un impulso inconsciente, ciego e irresistible, como lo vemos todavía en la naturaleza inorgánica y vegetal y en sus leyes, así como en la parte vegetativa de nuestra propia vida, adquiere, con la agregación del mundo 
representativo que se ha desarrollado para su uso, consciencia de su querer y de aquello que quiere que no es otra cosa que el mundo, la vida tal como se nos presenta (p.396).

Para Mèlich, lo que Schopenhauer entiende por voluntad es también un impulso ciego, un deseo que anhela sin descanso, sin una meta, insaciable...algo que carece de objetivo y de fin últimos, porque es un incesante anhelo (p.199).

A la vez, vemos que Mèlich enlaza el concepto de voluntad formulado por Schopenhauer con el pensamiento de $\mathrm{E}$. Bloch en lo que respecta al anhelo, puesto de relieve principalmente por éste último en su extensa y magna obra El Principio Esperanza (1959), y por esto considera que el anhelo, el deseo que siempre es deseo es consubstancial al ser humano y mantiene una constante tensión dentro de nosotros mismos; nunca estamos satisfechos en cómo somos y perseguimos una imagen inalcanzable, jamás nos basta con lo que encontramos en nuestra búsqueda desesperada, somos seres finitos con ansias de infinito. En este sentido, Mèlich cita la frase de Bloch (1959) no hay hombre que viva sin soñar despierto (vol. I p.26), que Mêlich deja inconclusa. Pero yo pienso que para nosotros, los psicoanalistas, merece ser transcrita la continuación de la frase de Bloch, [y] de lo que se trata es de conocer cada vez más estos sueños, a fin de mantenerlos así dirigidos a su diana eficaz y certeramente. Para Mèlich, como para mi, el anhelo del que nos habla Bloch mantiene nuestra vida en un estado de deseo y de insatisfacción constante. Lo expone Mèlich con estas sugeridoras palabras:

Somos seres fracturados, insatisfechos con el mundo heredado, deseosos de ser de otro modo, de habitar otro mundo, de vivir otra vida. Ahora bien, el deseo es deseo de algo que nunca es del todo conocido de antemano (por eso no es ni programable ni planificable), ni puede ser definitivamente alcanzado. Deseo...pero ¿qué es lo que deseo? La mayor parte de las veces uno es incapaz de dar respuesta a esta pregunta. Hay algo en la vida, una presencia extraña que nos habita desde el principio, que forma parte de nuestra existencia. No puedo llegar a ser yo - mismo de forma definitiva, no poseo algo propio sin que se encuentre roto por la inquietud, no alcanzo algo nuevo que logre calmar y saciar el deseo. Es entonces cuando descubro que éste resulta inseparable del sufrimiento. El ser humano es homo patients porque es un ser deseante (p.19).

Para este autor no sufrimos únicamente porque sabemos que moriremos frente a nuestros deseos de infinito, por la contingencia de nuestra vida y porque nos vemos abrumados por las circunstancias más diversas y por lo imprevisible de nuestra existencia, sino también porque no podemos evitar los afectos y las pasiones en nosotros mismos y, como consecuencia de ello, vivimos siempre en fractura, porque estamos en despedida, 
porque no sabemos verdaderamente lo que es este deseo y porqué nunca podrá ser saciado.

Por tanto, creo posible aseverar que los humanos somos seres fundamental y eternamente buscadores de algo que anhelamos. Nos cuestionamos a nosotros mismos, a los otros y al mundo, cosa que nos distingue de los animales que se mueven únicamente a merced de su instintividad, pero nosotros nos planteamos interrogantes, alternativas $y$ toma de decisiones que contribuyen a nuestro estado de tensión y a nuestro sentimiento de contingencia. Este sentimiento surge del hecho de que estamos siempre expuestos a lo que sucede, a lo que se presenta y me golpea, algo que sufro y padezco sin que pueda evitarlo, y la contingencia es, también, nuestra propia finitud. Consecuentemente, hemos de entender la ética, que no tiene que ver con la moralidad normativa, desde la perspectiva de este estado de incertidumbre, búsqueda, anhelo insatisfecho, fractura y deseo atormentador en el que vivimos hombres y mujeres.

Así, desde la perspectiva que acabo de exponer, una ética de la compasión es una ética de la situación y de una respuesta al otro que sentimos ineludible, mucho más allá del imperativo categórico y de lo que llamamos la moral y las normas obligatorias para todos. Es una ética que no pide nada a cambio y totalmente alejada del "doy esperando que me devuelvas", una ética que no demanda la reciprocidad. La ética de la compasión tampoco es piedad, porque el que experimenta piedad se siente por encima del que sufre, ni tampoco es ponerse en el lugar del otro, sino al lado del otro, para compartir con él/ella.

Por todo lo dicho, pienso que la ética que nos interesa como analistas tiene poco que ver con la ética formal en la que se nos indica la manera como debemos actuar, la que conocemos con el nombre de moral, sino que es aquella que surge de la demanda del paciente y ante la que no sabemos, a priori, cual es la respuesta adecuada y frente la que sentimos temor e incertidumbre; es la ética que nos insta a estar con el otro y a sentir compasión por su dolor, con la esperanza de que esta forma de proceder será la que más se acercará, aunque siempre quedará una distancia que nunca puede salvarse, a la respuesta que satisfaría por entero la demanda y a la que hemos de buscar por encima de todo, aun a sabiendas de que nunca la alcanzaremos por completo.

Antes de pasar a hablar más directamente de algunos aspectos de la trascendencia en el ser humano, vista desde la perspectiva del psicoanálisis relacional, deseo referirme a la interesante y original obra de Heinrich Rombach, Catedrático de Filosofía que fue en la Universidad de Wurzburgo (de1964 a 1990), El Hombre Humanizado. Antropología Estructural (1997), aunque hasta el momento ha tenido muy poca difusión en España, posiblemente debido a su pensamiento muy abstracto y su difícil lectura. Pero cumplo con 
esta referencia porque considero que en la visión del hombre humanizado que nos ofrece este autor se encuentran diversas ideas que a mi juicio concuerdan con los fundamentos y objetivos del psicoanálisis relacional y nos ayudan a enlazar ética y trascendencia. Así podemos verlo cuando en diversos momentos del texto Rombach se refiere al hombre como un ser en evolución que se encuentra, en la actualidad, en un momento de cambio, ya que él considera que el nombre genérico de hombre se ha dado de forma tal vez precipitada, antes de que se apoderará de toda la esencia para la que tiene capacidad (xxvii), debido a lo cual este autor trata, más que de describir al hombre tal como es, de apuntar a las posibilidades futuras en su evolución. Por ello, el hombre, en el pensamiento de Rombach, más que tener una tarea ante sí es esencialmente una tarea, responsable de su apariencia y de su esencia (p.18). Remarca más adelante:

El hombre no existe sin una imagen del hombre. El hombre no vive al día tal y como se presentan las cosas, sino que vive orientado, mirando hacia un mundo de tareas, basándose en un conjunto de premisas formado por condiciones y posibilidades, es decir, bajo la luz de un proyecto de ser, sea o no consciente de ello. El hombre percibe que sus acciones son humanas sólo cuando expresan, implícita o explícitamente, este proyecto de esencia; no deben corresponderse sólo con un único objetivo sino que también deben servir al objetivo global de la existencia humana y de la humanidad (p.19; destacados del autor).

A mi entender, el Hombre Humanizado que nos presenta Rombach concuerda con los objetivos del psicoanálisis relacional y lo enriquece, porque en este último, sin menoscabo de atender el pasado para la total comprensión del paciente, nos planteamos, como objetivo irrenunciable, despertar en él capacidades y anhelos que permanecían dormidos bajo el peso del sufrimiento, del temor y de las medidas defensivas ante el dolor y, por tanto, nos esforzamos en que surja su verdadero self al que, dentro de los límites que sean, podemos considerar equiparable a la esencia de la que nos habla Rombach. El ser humano es contingente $y$ en tanto que psicoanalistas sabemos que nunca puede ser librado por completo del sufrimiento, y de lo que se trata es que este sufrimiento sea creativo y en este intento creo que también pueden coincidir e iluminarse mutuamente el psicoanálisis relacional y este movimiento del hombre en busca de su esencia, a la que Rombach identifica como estructura. Pero a ésta no la ve como algo fijo e inamovible, sino que nos dice que la estructura:

...consta de varios escalones, es un agregado de momentos muy diferentes, es una estructura que fluye y se modifica constantemente, disoluble y perecedera ( $p .17$; destacado del autor). 
La obra de Rombach también se encuentra muy impregnada de la perspectiva de la unidad del Universo propia de los pensadores del "lejano oriente" ${ }^{4}$, especialmente el budismo, como podemos ver cuando dice con relación a ello:

...hay una "nada" que se contrapone a un ser; pero también hay una "nada" que es la abundancia y el origen de toda realidad... Esta "nada activa" es el punto decisivo del budismo. Por esto es de caudal importancia una apertura del pensamiento occidental hacia Oriente y el lejano Oriente (p. 214).

Rombach concibe al hombre como formando una unidad inseparable con la naturaleza y aun con la totalidad del cosmos. Esta perspectiva podemos verla en una de sus muchas referencias acerca de cómo concibe al hombre humanizado:

El "hombre humanizado" entiende su atributo de tal manera que constituye la característica más íntima de toda realidad. Todo el cosmos tiene forma humana, sólo por esto el hombre puede tener forma cósmica (universal). El hombre humanizado es el hombre cósmico, que se ve en correspondencia e intercambio con la naturaleza y con toda la realidad y se exige de sí mismo unos cumplimientos con todo lo demás muy concretos. En este sentido él es el hombre "natural" que se relaciona de tal modo con la naturaleza que ella consigue imponerse dentro de él. Se encuentra con la naturaleza naturalmente para que ésta se encuentre con él humanamente. En este sentido, la moralidad de lo "humano" va más allá de lo simplemente ético y une al hombre con el cosmos... Sólo cuando el hombre se comprenda como una configuración vital de la vida universal, y cuando haya aprendido a vivir en y para sí esta vida universal en configuraciones concretas y determinadas, solamente entonces podrá encontrarse con la naturaleza y sus iguales de manera que uno fomente al otro y cada uno se abra en el otro (p.436).

Así, pienso que este preclaro filósofo y antropólogo nos acompaña para entrar ya de lleno en el terreno de la trascendencia, en el psicoanálisis como en la propia vida, entendiendo por trascendencia, desde la psicología, el acto mental que se dirige más allá de los límites de la naturaleza humana y de la propia experiencia. Y digo esto porque el hecho de estar al lado del otro al que antes me he referido, el sentir compasión y que la apelación del otro provoca en mi un afecto del que no puedo desprenderme y que me obliga a una respuesta cuyo contenido todavía ignoro y que, tal vez, me atemoriza, pero que me vincula afectivamente de manera inevitable, y este reconocer la alteridad del otro junto a su ser igual a mí pero distinto de mí, me conducen al reconocimiento pleno de mi ser trascendente. $Y$ yo deseo subrayar que esta respuesta ética de estar emocionalmente al lado del que sufre nos concierne también a nosotros, en tanto que psicoanalistas, dentro de nuestras posibilidades y límites y en consonancia con la demanda de ayuda que nos dirige 
el paciente, llevado por su dolor. (Orange, Atwood y Stolorow, 1997 ; Piontelli, 1992; ; Siegel, 2007; Gerhard, 2008; Riera, 2010; Ávila-Espada, 2011; Schore, 2012; Wallin, 2012). Con todo ello, quiero insistir en que, para mí, la situación analítica no debe ser algo artificiosamente creado por el encuadre y como desgajado de la vida real del paciente, como tanto se ha insistido desde el psicoanálisis convencional, sino que, por el contrario, es y ha de ser una experiencia más, buena o mala, beneficiosa o perjudicial, totalmente inserta en la existencia del paciente, y sus efectos, curativos o nocivos, repercutirán en la realidad de su vida.

Junto al impulso al más allá de nosotros que nos dirige al otro, se nos muestra una peculiar dimensión de la trascendencia, la creencia en un Dios o Ser Supremo, presente siempre de una forma $u$ otra en todas las culturas conocidas y que en la historia de la humanidad ha recibido diversos nombres, pero dado que no existen pruebas empíricas que testifiquen su existencia, ni pruebas empíricas que la refuten- aunque algunos han alardeado últimamente de contar con estas últimas mediante la genética (Dawkins, 2007,2008)- juzgo que este tema pertenece al capítulo de la Fe, cuestión ésta totalmente personal y que permanece ajena a la ciencia. Pienso que de una manera parecida se expresa L. Wittgenstein (1921), quien considera que donde terminan las teorías científicas comienza lo místico, lo inefable, lo indemostrable, y dice en el punto 6.44 del Tractatus (1921): Lo que es místico no es cómo es el mundo, sino que el mundo es. Y yo pienso que lo mejor es que aquí siga yo la advertencia 6.54 de Wittgenstein, con la que termina el texto, cuando dice: De aquello de lo que no se puede hablar es mejor guardar silencio. Pero creo que se interpretará mejor mi propia posición personal en cuanto a la grandísima importancia de aquello de lo que no se puede hablar si nos atenemos a un punto anterior del Tractatus, el 6.52, en el que expresa: Tenemos la sensación de que incluso cuando todas las posibles preguntas científicas han sido contestadas, aun no se han tocado para nada nuestros problemas vitales. Bien cierto, entonces ya no resta, justamente, ninguna otra pregunta; y precisamente esto es la respuesta (resaltado del autor).

Puede, con razón, decirse que existen otros campos, además de la búsqueda del otro, en los que se manifiesta la trascendencia, como son el arte, la música, la poesía y la ciencia, pero yo no creo que la fuerza que impele a quienes tales actividades cultivan sea algo distinto a la búsqueda de la alteridad, del contacto y la comunicación interpersonal y social, porque afirmo que no hay actos psíquicos no relacionales $y$, por tanto, a mi juicio estas actividades son siempre una forma de contacto y comunicación con los otros porque, incluso en el caso que alguno las mantenga en silencio, en su mente son acto relacionales, por tanto, son actos trascendentes dentro del nivel humano. 
Esta realidad se expresa siempre en las relaciones interpersonales. Como una oportunidad muy a mano subrayo que a ellas está dedicada la excepcional y completísima obra de la que es editor y co-autor A. Ávila-Espada, La Tradición Interpersonal (2013). Así mismo, no cabe duda de que toda patología psíquica se expresa en la relación con los otros, cuestión ésta que se encuentra exhaustivamente tratada por J. L. Tizón en sus cuatro volúmenes de Apuntes para una Psicopatología Basada en la Relación (2018-2019).

Algo parecido, con relación a la necesidad de unión que nos impele a luchar contra una fuerza que divide y separa, encontramos en Loewald, para mí uno de los más importantes psicoanalistas del pasado siglo, y al que creo que no se le ha dado la atención que merece, posiblemente porque aun cuando su pensamiento es netamente relacional parece que se siente obligado a esconderlo, escudándose bajo un lenguaje clásico. Como ya expuse en otro momento (2010), fue uno de los primeros autores que empleó el término interacción aplicado a la relación paciente - analista, y en comprender la gran importancia de la misma en cuanto a las posibilidades de modificación de la mente de ambos. Afirma que la mente humana se forma a través de la interacción, y que es a través de ella la manera como se produce su modificación. Otro punto que me parece de gran interés en lo que concierne a la trascendencia es la visión cosmológica de Loewald y sus palabras acerca de la constante dialéctica entre unidad y separación en la estructura de la mente humana, previamente compactada en una densidad primaria $(1960,1978,1979)$.

Ayudará al terapeuta a percibir las ansias de trascendencia del paciente en sus más diversas expresiones, que no procede ahora repetir, no el tratar de hacer encajar la narrativa del paciente en su propias teorías, sino el ayudarle a sentir que le acompaña respetuosamente en su relato; no sólo que escucha y comprende, sino que está a su lado y le acoge, y creo que cobra gran importancia el hecho de que aquél perciba que el terapeuta da más valor a sus pensamiento, en tanto que ser libre e independiente, que a los propios, y que en los momentos difíciles abandona el Libro por el que se guía para relacionarse con su paciente en tanto que persona única e irrepetible que es(Hoffman, I. 1998;Coderch, J., 2018).

Pero, además, hay otra dimensión de la personalidad humana que favorece tanto la configuración y desarrollo de la trascendencia como su plena llegada a la consciencia, e incrementa la posibilidad de que se manifieste visiblemente en el diálogo paciente- analista. Con esto último me refiero a la capacidad de excentricidad por parte de los seres humanos, cosa que les distingue radicalmente de todos los otros seres vivientes, capacidad ésta que ha sido especialmente estudiada y puesta de relieve por Helmut Plessner (1991). Expresa este autor que el ser humano ocupa, respecto al resto de los seres vivos, una posición 
excéntrica, porque no debe atenerse exclusivamente a un "centro" único, cosa que sí les sucede a los animales sujetos a su instintividad, sino que puede descentrarse, o sea, hacerse excéntrico a sí mismo y tomar distancia, autorreflexivamente, respecto a su propio sentir y pensar, de manera que, en función de tal capacidad, les es posible a hombres y mujeres diferenciar no solo entre ellos y su contexto o contextos, sino también entre su self central, sus percepciones y sus experiencias más íntimas y profundas, digamos sus otros selves (Bromberg, 2011), Así, el ser humano, dado que es consciente de su centro y de la periferia del mismo, tiene la posibilidad de someter al mundo de la realidad y, a sí mismo, a una reflexión crítica desde el exterior, tomar distancia y posicionarse respecto a los deseos que en él anidan y que le impulsan a buscar otro centro y a trascender los límites que a ellos se oponen.

Finalmente, pienso que en lo que concierne a la actividad mental no hay un fenómeno en el que la cualidad trascendente del ser humano se manifieste con mayor claridad que en la simbolización. Me parece que esta afirmación queda clara si partimos de la idea de que la función simbólica es la capacidad inherente a la condición humana de hacer presente y dar vida al ausente y, por tanto, de hacerlo presente de una manera mediata (Lluch, 1991; Lluch y Chillón, 2012). Sí esto es así, podemos decir que el símbolo es el representante de lo que se encuentra ausente. A diferencia del signo, que es unívoco e indica siempre lo mismo dentro de cada cultura, el símbolo es equívoco, porque puede ser interpretado de distintas formas según las diferentes situaciones, deseos, sueños, fantasías, temores, leyendas, etc., vigentes en la cultura del intérprete, de manera que nos encontramos con que si no hay posibilidad de interpretación es que no hay símbolo, porque lo que siempre deseamos y pretendemos es ir más allá, llegar a un bien que no conocemos pero que intuimos, como es la posibilidad de comunicarnos mejor, de conocer lo desconocido, de alcanzar un no sabemos qué, pero puesto que no podemos traspasar nuestros límites recurrimos a los símbolos y mediante ellos construimos nuestro Universo en la ciencia, en el arte, en la historia, en el drama, en la sociedad, en la música, en la poesía. Estamos obligados a ello porque no disponemos de un acceso inmediato a la realidad- ni tan solo a la nuestra- y frente a ella nos hemos de conformar con un acceso mediatizado y captarla a través de unos artefactos simbólicos los cuales, aunque siempre dependientes en su manifestación del contexto tradicional y cultural en el que cobran forma, son la expresión, en último término, de una necesidad de trascendencia siempre viva en nuestra naturaleza.

Y con lo que acabo de exponer nos encontramos de nuevo con el deseo que siempre es deseo, compañero en todo momento de los seres humanos, porque palpita en nosotros perennemente el sentimiento de algo que se ha perdido, de la antigua existencia de una unidad que se ha disuelto y que nos empuja a buscar sin cesar esta unidad perdida. El 
símbolo, por tanto, pone al descubierto que la relacionalidad, ya sea de tipo afectivo, amoroso y social, o de enemistad y beligerancia, constituye la expresión antropológica más auténtica de la trascendencia en la existencia humana (Aron, 1996, 2001; Critchley, 2007). Siguiendo la línea del pensamiento de Bloch, podemos ver al símbolo como una constante apelación al recuerdo del ausente, al deseo insaciable del ausente, cosa que permite que en el ser humano acontezca la posibilidad del soñar despierto y que en este sueño, por fin, la libre fantasía se imponga a la realidad.

Pero la condición para que el soñante no despierte, despavorido y desalentado, es la de que el símbolo no se convierta en realidad, en la áspera realidad, en la insolente realidad que quiebra nuestras ilusiones, porque entonces lo que se soñaba como un bien inaccesible e ideal se evapora y, así como los pétalos de una sensitiva flor se abren a la dulce y tenue luz del alba, y presto se cierran al sentir la herida de los rayos del sol, también lo soñado desaparece ante la fealdad, miseria y pobreza de lo malo y perecedero. Porque, inexorablemente, persiste siempre en los seres humanos el deseo que siempre es deseo, este deseo que nunca descansa y se encuentra en las leyendas del paraíso perdido que ha de ser recobrado presentes en todas las civilizaciones, el deseo que nunca será colmado y siempre se verá burlado, porque su misma ubicuidad e inmaterialidad hacen imposible su satisfacción ante tan desmesurada demanda. Porque el ser humano exige acceder a la totalidad de la realidad, al sentido último de la existencia, a la conciliación de sus contradicciones internas, al bienestar físico, al poder total sobre la naturaleza, a ser infinito y a vencer a la muerte, y esto es solamente un sueño, tal vez el sueño perpetuo que alimenta el Romanticismo, siempre presente bajo diversas formas en nuestra cultura en su perenne dialéctica con la gélida Ilustración.

Concluyo afirmando que la ética en psicoanálisis afianza sus raíces en la compasión ante la llamada inextinguible del otro que sufre, y tengo en mi que esta ética sólo es posible si el analista, en lugar de escudarse fríamente en fórmulas de una pretendida neutralidad, que sólo es cruel indiferencia, atiende a la demanda de ser querido y al anhelo de trascendencia del paciente, de ir más allá de los límites de la propia individualidad, al anhelo que es consubstancial a la naturaleza humana, y entonces, pero sólo entonces, ética y trascendencia se conjugan y alimentan mutuamente, para el bien del paciente y aun del propio analista.

\section{REFERENCIAS}

ARON, L. (1996,). The Meeting of the Minds, Hillsdale,NJ: The Analytic Press. 
ARON, L. (2006). Analytic impasse and the third, Int. J. Psychoanal, 349-368.

ÁVILA-ESPADA, A. (2011). Dolor y sufrimiento psíquico, Clínica e Investigación Relacional, vol.5 (1), 125-149.

ÁVILA-ESPADA, A. (Ed.) (2013) La Tradición Interpersonal. Perspectiva Social y Cultural del Psicoanálisis, Madrid: Ágora Relacional.

BLOCH, E. [1959]. El Principio Esperanza, Madrid: Editorial Trotta, 2000

BROMBERG, P. [ 2001]. La Sombra del Tsunami y el Desarrollo de la Mente Relacional, Ágora Relacional, 2017.

CODERCH de SANS, J, (2006), Pluralidad y Diálogo en Psicoanálisis, Ed. Herder

CODERCH de SANS, J. (2010). La Práctica de la Psicoterapia Relacional, Madrid: Ágora Relacional.

CODERCH de SANS, J. (2018a). La apertura a la realidad social y personal de los hombres y de las mujeres, Clínica e Investigación Relacional, vol.12 (1),pp. 11-28.

CODERCH de SANS, J., (2019). El amor y las relaciones humanas, Temas de Psicoanálisis.org .(1),pp.11-18.

CODERCH de SANS, J., y CODOSERO MEDRANO, A. (2012). Realidad, Interacción y Cambio Psíquico. La Práctica de la Psicoterapia Relacional 11, Madrid: Ágora Relacional.

CODERCH de SANS, J. (Coord.), CASTAÑO CATALÁ, R., CODOSERO MEDRANO A., DAURELLA de NADAL, N. y RODRÍGUEZ-SUTIL, C. (2014). Avances en Psicoanálisis Relacional, Madrid: Ágora Relacional

CODERCH de SANS, J. y PLAZA ESPINOSA A. (2016). Emoción y Relaciones Humanas, Madrid: Ágora Relacional.

CODERCH, de SANS, J. (Coord.), CODOSERO MEDRANO, A., DURELLA de NADAL, N., PLAZA ESPINOSA, A., SUNYÉ i BARCONS, T. (2018). Las Experiencias Terapéuticas en el Proceso Psicoanalítico, Madrid: Ágora Relacional.

CRITCHLEY, S. [2007]. La Demanda Infinita. La Ética del Compromiso y la Política de la Resistencia, Barcelona: Marbot, 2017.

DAURELLA, N. (2013). Falla Básica y Relación Terapéutica, Madrid: Ágora Relacional.

DAURELLA, N. (2018). Transferencia y contratransferencia desde la perspectiva del psicoanálisis relacional: a la búsqueda de la responsividad óptima, Aperturas Psicoanalíticas, 59, pp. 1-21.

DAWKINS, R. (2007).El Espejismo de Dios, Madrid: Espasa-Calpe.

DAWKINS, R. (2008). El Gen Egoista, Barcelona: Salvat.

DUCH, LI, (1999). Sinbolisme i Salut, Antropologia de la vida quotidiana 1, Publicacions de l'Abadia de Montserrat. 
DUCH, LI. (2000). Llums i Ombres de la Ciutat. Antropologa de la Vida Quotidiana, 3.

Publicacions de l'Abadia de Montserrat.

DUCH, LI. (2010). Religió I Comunicació, Barcelona: Fragmenta Editorial

DUCH, LI y MÉLICH, J.C. (2004). Ambigüitats de l'Amor, Antropologia de la Vida Quotidiana, 2,2, Publicacions de l'Abadia de Montserrat.

DUCH, LI. y CHILLÓN, A. (2011). Un Ser de Mediaciones. Antropología de la Comunicación, Barcelon: Herder.

FERENCZI, S. (1929). El niño no bienvenido y su impulso de muerte, en Obras Completas, vol.4

FERENCZI, S. (1930). Principio de relajación y neocatarsis, en O.C., vol. 4.

FERENCZI, S. (1931). Análisis de niños con los adultos, en O.C., vol.4.

FERENCZI S. (1932). Confusión de lenguas entre los adultos y el niño, en O.C., vol.4

FERENCZI, S. [1932]. Sin simpatía no hay curación, Buenos Aires: Amorrortu Editores., 1997.

FROMM, E. [1947]. El Miedo a la Libertad, México: Fondo de cultura Económico, 1953-.

GERHARD, S. [208]. El Amor Maternal, Barcelona: Ed. Albesa.

HOFFMAN, I. (1998). Ritual and Spontaneity in the Psychoanalytic Process, Hillsdale, NJ: Analytic Press.

LOEWALD, H, (1960). On the therapeutic action of psychoanalysis, Papers on Psychoanalysis, New Haven and London, pp. 221-256.

LOEWALD, H. (1978). Primary process, secondary process and language, Papers on Psychoanalysis, New Haven and London, pp. 178-206.

LOEWALD, H, (1979), Reflections o the psychoanalytic process and its therapeutic potencial, New Haven and London, pp.372-383.

MÈLICH, J.C. (2010). La Ética de la Compasión, Barcelona: Herder.

ORANGE, D. (2006). For whom the bells told; context, complexity and compassion in psychoanalysis, Int. Psychoanal. Self Psycho. ,1:5-21. OJO

ORANGE, D. ([2010]. Pensar la Práctica Clínica, Santiago de Chile: Ed. Cuatro Vientos,2012.

ORANGE, D. (2016). Una actualización: De la teoría de los sistemas intersubjetivos al Giro Ético en psicoanálisis, Clínica e Investigación Relacinal, vol.10, pp. 27-48.

ORANGE, D. (1012). Hospitalidad Clínica. Acogiendo el Rostro del Otro devastado, Clínica e Investigación Relacional, vol.7 (1): 11-24.

ORANGE, D., ATWOOD, G. y STOLOROW, R. [1997]. Trabajando Intersubjetivamente, Madrid: Ágora Relacional, 2012.

PIONTELLI, A. [1992]. Del Feto al Niño, Barcelona: Ed. Albesa. 
PLESSNER, H. (1991). “Conditio Humana”: G.Mann - A.Heuss ((ed). Historia Universal. I. 1. Prehistoria. Las primeras culturas superiores-, Madrid: Espasa-Calpe, 1991, 37.

RIERA, R. (2010). La Connexió Emocional, Barcelona: Ed. Octaedro.

RODRÍGUEZ-SUTIL, C. (2014). Psicopatología psicoanalítica relacional, Madrid: Ágora Relacional.

ROMBACH, H. [1994]. El Hombre Humanizado. Antropología estructural, Barcelona: Herder, 2004.

SASSENFELD, A. (2018). Los giros del psicoanálisis contemporáneo, Clínica e Investigación Relacional, vol,12 (2),pp.268-316.

SCHOPENHAUER, A. (2008). El Mundo como Voluntad y Representación, Buenos Aires: Editorial Losada.

SCHORE, A. (2012). The Science of the Art of Psychotherapy, Londres: W.W. Norton \&Company.

SIEGEL, D. [1999]. La Mente en Desarrollo, Bilbao: Ed. Desclée De Brouwer, 2007).

SLOCHOWER, J.(2018). No se lo digas a nadie, CelR, vol.12 (3), pp.419-435.

TIZÓN, J. (2018-2019). Apuntes para una Psicopatología Basada en la Relación. Variaciones Psicopatológicas, vol. 1., Psicopatología General, Barcelona: Herder.

TIZÓN, J. (2018-2019). Apuntes para una Psicopatología Basada en la Relación, vol.2., Relaciones dramatizadas, atemorizadas y racionalizadoras; Barcelona: Herder.

TIZÓN, J. (2018-2019). Apuntes para una Psicopatología Basada en la Relacion. vol.3, Relaciones emocionalizadas, intrusivas, actualizadoras y "operatorias"; Barcelona: Herder.

TREVARTHEN, C. [2009]. La psicobiología del significado humano: El aprendizaje de la cultura depende del interés en el trabajo práctico cooperativo y del cariño por el gozoso arte de la buena compañía, Clínica e Investigación Relacional, vol.5 (1), pp.17-33.

WALLIN, D. (2012). El Apego en Psicoterapia, Bilbao: Ed. Desclée de Brouwer.

WITTGENSTEIN, L. [1921]. Tractatus Logico Philosoficus, Barcelona: Editorial Crítica, 1988.

Original recibido con fecha: 19/4/21 Revisado: 17/6/21 Aceptado: 30/06/2021

NOTAS:

${ }^{1}$ Trabajo leído como conferencia de clausura en las VI Jornadas de Psicoanálisis Relacional, que sobre el lema: "Winnicott en el Psicoanálisis Relacional Actual: Creatividad, intersubjetividad y el jugar en la clínica" se realizaron online desde Barcelona, los días 14 y 15 de Mayo 2021, organizadas por el Instituto de Psicoterapia Relacional y el Institut Català D. Winnicott.

2 Joan Coderch de Sans (Hospitalet de Llobregat, Barcelona, 1930). Doctor en medicina y miembro titular de la Sociedad Española de Psicoanálisis (de la que ha sido presidente) y de la Asociación Psicoanalítica Internacional. Ex -Profesor Adjunto de Psiquiatría de la Universidad de Central Barcelona, Profesor Emérito de la Universidad

@ Derechos reservados/Copyright de Clínica e investigación Relacional y los autores. Prohibida la reproducción total o parcial sin autorización expresa. Este material es para uso científico y profesional exclusivamente y puede contener información clínica sensible. Los editores no se responsabilizan de los contenidos de los autores. Dirigir las consultas sobre derechos y autorizaciones a ceir@psicoterapiarelacional.es 
Ramón Llull. Ha publicado los siguientes libros: Psiquiatría Dinámica (1975), Herder, segunda ed. modificada, 2012; Teoría y Técnica de la Psicoterapia Psicoanalítica (1987),Herder; La Interpretación en Psicoanálisis (1995), Herder; La Relación Paciente- Terapeuta (2001), Fundació Vidal i Barraquer-Paidós, (2012), Herder; Pluralidad y Diálogo en Psicoanálisis (2006), Herder; y los más recientes: La Práctica de la Psicoterapia Relacional (2010); Realidad, Interacción y Cambio Psíquico (2012); Avances en Psicoanálisis Relacional (2014); Emoción y Relaciones Humanas (2016, con Alejandra Plaza); Las experiencias terapéuticas en el proceso psicoanalítico (2018, con varios autores), y Esbozo de autobiografía. Memoria de las experiencias que han dado sentido a mi vida (2020) todos ellos publicados en Madrid: Ágora Relacional. Contacto: 2897jcs@comb.cat

3 Además del Diario Clínico, deseo señalar que para mí los trabajos más significativos de Ferenczi- seguramente por una cuestión antes que nada emocional- son: El niño no bienvenido y su impulso de muerte,(1929), Análisis de niños con los adultos ( 1931), Confusión de lenguas entre los adultos y el niño (1932) y Principio de relajación y neocatarsis (1932).

${ }^{4}$ Las obras de Rombach han despertado el interés de muchos pensadores orientales, especialmente japoneses. Varias de ellas han sido traducidas al japonés. 